\title{
Synthesis and Characterization of $\mathrm{ZrO}_{2}$ Nanoparticles using Microwave Assisted Method and Its Antimicrobial Activity
}

\author{
S. Baby Asha ${ }^{1}$, D. Muthuraj1,*, E. Kumar², V. Veeraputhiran ${ }^{3}$ \\ ${ }^{1}$ PG and Research Department of Physics, The M.D.T. Hindu College, Tirunelveli - 627 010, Tamilnadu, India. \\ ${ }^{2}$ Department of Physics, School of Science, Tamil Nadu Open University, Chennai - 600 015, Tamilnadu, India. \\ ${ }^{3} R$ \& D Department, Alba Industries Pvt. Ltd., Thoothukudi - 628 103, Tamilnadu, India.
}

\section{ART I C LE DET A ILS}

\section{Article history:}

Received 05 March 2019

Accepted 27 March 2019

Available online 31 March 2019

Keywords:

Zirconium Dioxide

Microwave Method

Antimicrobial Activity

\section{A B S T R A C T}

Zirconium dioxide $\left(\mathrm{ZrO}_{2}\right)$ nanoparticles have been synthesized via microwave assisted method. The structural analysis was carried out using X-ray diffraction. It showed that the $\mathrm{ZrO}_{2}$ nanoparticles exhibited monoclinic structure. The morphological studies revealed that the particles were spherical in structure and slightly agglomerated. The $\mathrm{ZrO}_{2}$ product was investigated by FT-IR, UV, SEM and microbial activity studies.

\section{Introduction}

The $\mathrm{ZrO}_{2}$ nanoparticle is very interesting and valuable material for its fundamental application based properties. The synthesized metal oxide nanoparticles vary in physical, chemical, and morphological properties and are being used in various fields as they have various applications [1]. Thermodynamically most stable form of $\mathrm{ZrO}_{2}$ is monoclinic structure. Pure zirconia has high number of oxygen vacancies defects predominantly. The nano sized zirconia owing to large surface area has high number of oxygen vacancies at grain surface [2]. Therefore solid $\mathrm{ZrO}_{2}$ can conduct electricity up to some extent and it is considered as p-type semiconductor. The band gap value of $\mathrm{ZrO}_{2}$ depends upon synthesis temperature, particle size and crystalline structure. Numerous chemical methods have been reported to synthesize pure $\mathrm{ZrO}_{2}$, such as thermal decomposition [3], sol-gel methods [4], and hydrothermal techniques [5]. The as-prepared nanoparticles were extensively characterized using X-ray diffraction, FT-IR, UV, SEM and antimicrobial activity studies.

\section{Experimental Methods}

\subsection{Materials}

All the chemicals were used as analytical grade without any further purification. Zirconium oxy nitrate and ammonia were used to prepare the nanoparticles of this work. Double distilled deionized water used in this investigation. Disc diffusion method has employed with gram negative bacteria (Pseudomonas aeruginosa and Escherichia coli) and gram positive bacteria (Staphylococcus aureus and Bacillus subtilis).

\subsection{Synthesis}

All chemicals were analytical grade (AR) and used without further purification. Zirconium oxychloride and $\mathrm{NaOH}$ were used for the preparation of the zirconium oxide nanoparticle. In the present work 8.6 gm of zirconium oxychloride $\left(\mathrm{ZrO}_{2} 8 \mathrm{H}_{2} \mathrm{O}\right)$ was added with deionized water and stirred for homogeneous solution, during stirring $\mathrm{NaOH}$ solution was added till the $\mathrm{pH}$ value becomes 12 . After that white sol has been formed. This solution kept at microwave oven with minimum temperature at 6 minute. The prepared powder filtered with deionized water and dried at $50{ }^{\circ} \mathrm{C}$ for 1 hour. This powder calcinated $600^{\circ} \mathrm{C}$ for 4 hour.

\subsection{Instrumentation}

Powder X-ray diffraction pattern of the nanoparticles was obtained using a Rigaku Ultima IV powder X-ray diffractometer. The sample was scanned over the required range for $2 \Theta$ values. The FTIR spectrum of the sample was recorded within the wavenumbers from $4000 \mathrm{~cm}^{-1}$ to $400 \mathrm{~cm}$ ${ }^{1}$ by using Perkin Elmer Frontier FTIR. Optical properties were examined by UV-Vis spectrophotometer (UV-1800 PC Shimadzu). The antimicrobial activity was determined by disc diffusion method.

\section{Results and Discussion}

\subsection{X-Ray Diffraction Method}

Zirconium dioxide was synthesized by microwave assisted solution technique. The powder XRD pattern of the prepared $\mathrm{ZrO}_{2}$ nanoparticles is shown in Fig. 1 which shows a strong diffraction peaks along $28.28^{\circ}$, $24.16^{\circ}, 30.32^{\circ}, 34.2^{\circ}, 35.4^{\circ}, 50.19^{\circ}, 40.9^{\circ}, 45.6^{\circ}, 60.3^{\circ}[6]$, and $65.8^{\circ}$ with $\mathrm{h}$ $\mathrm{k} l$ values. The $\mathrm{ZrO}_{2}$ nanoparticles show a tetragonal phase from diffraction peaks at $30.32^{\circ}, 34.2^{\circ}, 50.19^{\circ}$, and $60.3^{\circ}$.

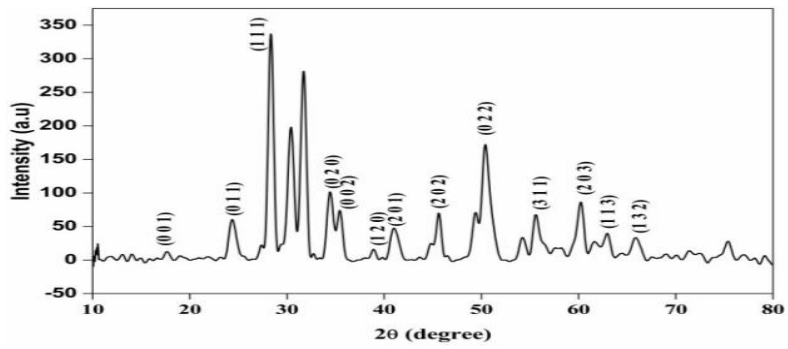

Fig. 1 XRD pattern $\mathrm{ZrO}_{2}$ nanoparticles

From the Fig. 1, the diffraction bands were confirmed by crystalline nature. The crystalline nature was confirmed to peaks at (001), (011), (111), (020), (002), (120), (201), (202), (022), (311), (203), (113) and (132). The indexed peaks are confirmed by monoclinic structure at (002), (202), (022), (311) and (113) [7]. These both structures were confirmed by SEM images. The broad diffraction bands shows the prepared samples 
are nano sized. The $\mathrm{ZrO}_{2}$ nanoparticle grain size was found as around 35 $\mathrm{nm}$. The grain size calculated formula is given below [8],

$$
\mathrm{D}=0.9 \lambda / \beta \cos \theta
$$

where $\lambda$ is incident $X$ - ray wavelength, $\beta$ is FWHM, and $\theta$ is diffraction angle. The average grain sizes of $\mathrm{ZrO}_{2}$ nanoparticles were calculated, from the diffraction bands.

\subsection{SEM Analysis}

The morphology of the prepared $\mathrm{ZrO}_{2}$ nanoparticle shows the particles are crystalline nature and looks like stony structure due to the high degree of agglomeration. Agglomeration occurred because of appropriate intermolecular attraction present between the prepared nanoparticles. From the SEM images, the particles size is found around 32 to $38 \mathrm{~nm}$. This observed size was confirmed as support from XRD analysis. The particles are confirmed as a randomly spherical shape from the image. SEM measurements were carried out on $\mathrm{ZrO}_{2}$ nanoparticles to uncover morphological differences between the two systems at the nanometer and micrometer scales. Fig. 2 shows the SEM micrograph at four different magnifications for $\mathrm{ZrO}_{2}$ nanoparticles.

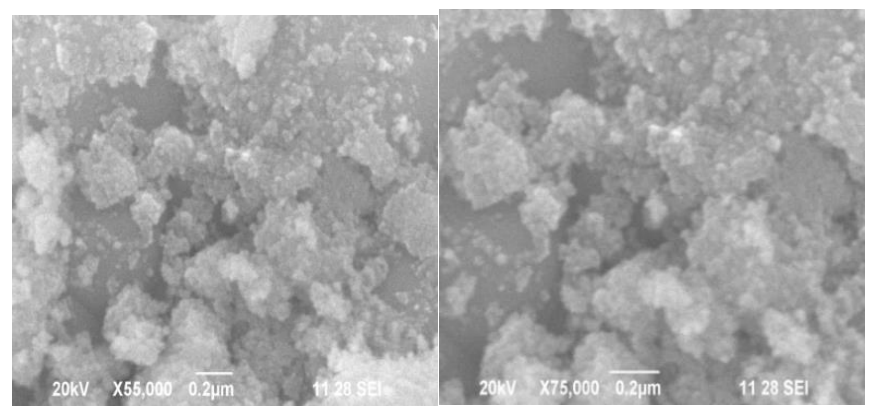

Fig. 2 SEM images of $\mathrm{ZrO}_{2}$ nanoparticles

\subsection{FTIR Characterization}

The chemical structures of $\mathrm{ZrO}_{2}$ nanoparticles are characterized by FTIR spectroscopy. FTIR study confirms the functional groups present in the prepared $\mathrm{ZrO}_{2}$ nanoparticles. Fig. 3 shows the FTIR spectrum of the prepared sample. The weak peaks from 3000 to $3500 \mathrm{~cm}^{-1}$ corresponds to the stretching vibrations of $\mathrm{O}-\mathrm{H}$ on surface of $\mathrm{ZrO}_{2}$ nanoparticle, while the peaks at $751 \mathrm{~cm}^{-1}$ and $577 \mathrm{~cm}^{-1} \mathrm{Zr}-\mathrm{O}_{2}-\mathrm{Zr}$ asymmetric and $\mathrm{Zr}-\mathrm{O}$ stretching modes respectively, confirms the formation of $\mathrm{ZrO}_{2}$ phases [9]. Weak bands observed at $1642 \mathrm{~cm}^{-1}$ and $3336 \mathrm{~cm}^{-1}$ are explain the stretching and bending vibrations of $\mathrm{O}-\mathrm{H}$ bands, show to water molecule as absorbed. The bands $1339 \mathrm{~cm}^{-1}$ is confirm to absorption of nonbridging $\mathrm{OH}$ groups. The very sharp peaks $751 \mathrm{~cm}^{-1}$ is occurred at characteristic of $\mathrm{m}-\mathrm{ZrO}_{2}$.

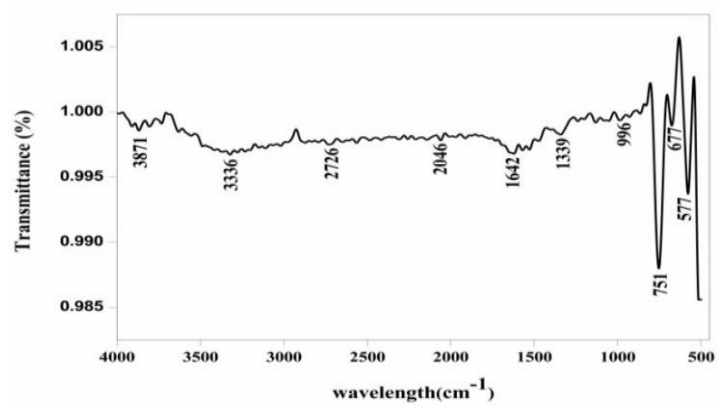

Fig. 2 FTIR spectrum of $\mathrm{ZrO}_{2}$ nanoparticles

\subsection{UV-DRS Analysis}

The UV-DRS spectra of the prepared $\mathrm{ZrO}_{2}$ nanoparticle as shown in Fig. 4. The optical band gap energy for the prepared $\mathrm{ZrO}_{2}$ sample was determined from diffuse reflectance spectra using Kubelka Munk equation,

$$
\left(\left(R_{\infty}\right) \cdot h \gamma^{2}\right)=A(h \gamma-E g)
$$

where $F\left(R_{\infty}\right)$ is the Kubelka- Munk function or reemission parameter, $h \gamma$ is the energy of incident photon, $R_{\infty}$ is the diffuse reflectance that is obtained from $R_{\infty}=R_{\text {sample }} / R_{\text {standard, }}$, and $A$ is a constant. The values of $\left(\left(R_{\infty}\right) . h \gamma^{2}\right)$ versus $h \gamma$ was plotted for the prepared sample as shown in Fig. 4. Straight line was drawn to fit the experimental curve, and was extended to cut off the $h \gamma$ axis, optical band gap energy value has been determined https://doi.org/10.30799/jnst.216.19050117 of $\mathrm{ZrO}_{2}$ nanoparticles. From the Fig. 4, the optical band gap of prepared $\mathrm{ZrO}_{2}$ nanoparticle has been $4.9 \mathrm{eV}$.

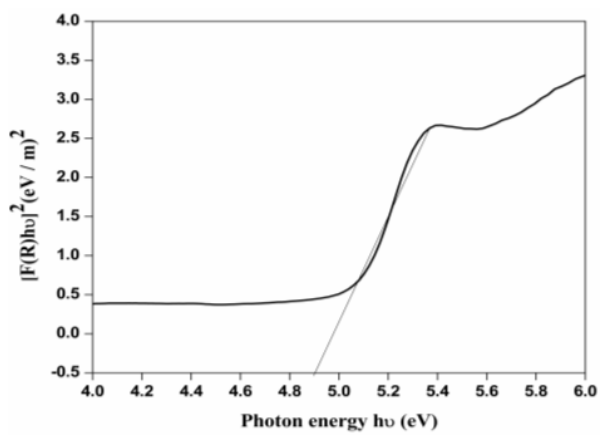

Fig. 4 UV DRS spectrum of $\mathrm{ZrO}_{2}$ nanoparticles

\subsection{Antimicrobial Activity}

The antimicrobial activity of $\mathrm{ZrO}_{2}$ was investigated against gram negative bacteria (Pseudomonas aeruginosa and Escherichia coli) and gram positive bacteria (Staphylococcus aureus and Bacillus subtilis), respectively. The prepared $\mathrm{ZrO}_{2}$ nanoparticles showed a good inhibitory action against Pseudomonas aeruginosa (inhibition zone size of $10 \mathrm{~mm}$ ) at the $100 \mu \mathrm{g} / \mathrm{mL}$ compared to other bacteria due to the negatively charged, $P$. aeruginosa cell wall readily attracting positively charged $\mathrm{ZrO}_{2}$, and in that way inhibiting microbial actions. In addition to that the $\mathrm{ZrO}_{2}$ nanoparticle was directly proportional to their inhibitory actions beside the tested microorganism. $\mathrm{ZrO}_{2}$ nanoparticles have confirmed that they have possible biomedical applications.

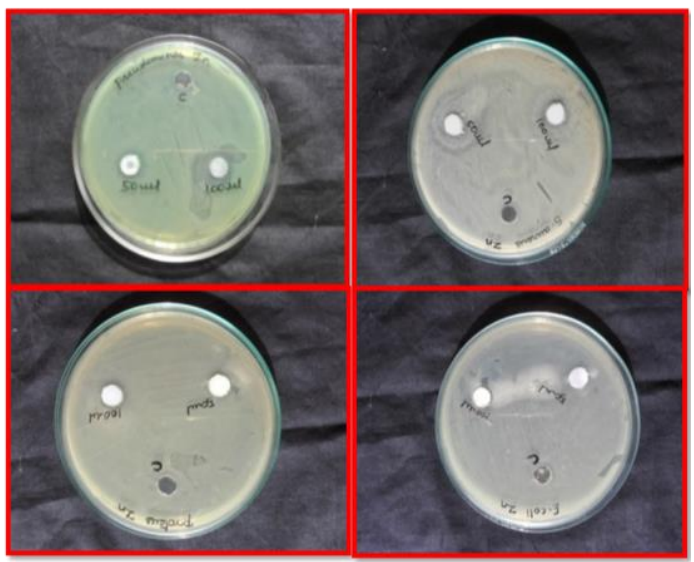

Fig. 5 Antimicrobial activity of $\mathrm{ZrO}_{2}$ nanoparticles

\section{Conclusion}

Zirconium dioxide was synthesized by microwave assisted solution technique. The indexed peaks are confirmed by monoclinic structure at (002), (202), (022), (311) and (113) the $\mathrm{ZrO}_{2}$ nanoparticle grain size was found as around $35 \mathrm{~nm}$. The morphology of the $\mathrm{ZrO}_{2}$ nanoparticle shows the particles are crystalline nature and looks like stony structure due to the high degree of agglomeration. The SEM images, of the $\mathrm{ZrO}_{2}$ particles size is around 32 to $38 \mathrm{~nm}$. The chemical structures of $\mathrm{ZrO}_{2}$ nanoparticle are characterized by FTIR spectroscopy. The weak peaks from 3000 to $3500 \mathrm{~cm}^{-1}$ corresponds to the stretching vibrations of $\mathrm{O}-\mathrm{H}$ on surface of $\mathrm{ZrO}_{2}$ nanoparticle, while the peaks at $751 \mathrm{~cm}^{-1}$ and $577 \mathrm{~cm}^{-1} \mathrm{Zr}-\mathrm{O}_{2}-\mathrm{Zr}$ asymmetric and $\mathrm{Zr}-\mathrm{O}$ stretching mods respectively, confirms the formation of $\mathrm{ZrO}_{2}$ phases. The optical band gap of prepared $\mathrm{ZrO}_{2}$ nanoparticle has been obtained as $4.9 \mathrm{eV}$. The antimicrobial activity of $\mathrm{ZrO}_{2}$ was investigated against gram negative bacteria (Pseudomonas aeruginosa and Escherichia coli) and gram positive bacteria (Staphylococcus aureus and Bacillus subtilis), respectively and leads the idea as they have possible biomedical applications.

\section{References}

[1] P.N. Kapoor, R. Ajay Kumar, S. Mulukulta, K.J. Klabunde, Mixed metal oxide nanoparticles, Dekker Encyclopedia of nanosciences and nanotechnology, 2004, pp.2007-2017.

[2] C.S.S.R. Kumar, Nanomaterials- Toxicity, Health and Environment Issues, Wiley-VCH, Germony, 2006 
[3] S. Vaidya, T. Ahamad, S. Agareal, Nanocrystalline oxalate/carbonate precursors of $\mathrm{Ce}$ and $\mathrm{Zr}$ and their decompositions to $\mathrm{CeO}_{2}$ and $\mathrm{ZrO}_{2}$ nanoparticles, J. Am. Ceram. Soc. 90(3) (2007) 863-869.

[4] Y.W. Zhang, Z.G. Yan, Liao FH, Citrate gel synthesis and characterization of $\left(\mathrm{ZrO}_{2}\right)_{0.85}\left(\mathrm{REO}_{1.5}\right)_{0.15}(\mathrm{RE}=\mathrm{Y}, \mathrm{Sc})$ solid solutions, Mater. Res. Bull. 39(11) (2004) 1763-1777.

[5] L. Kumari, D.H. Du, W.Z. Li, R. Selva Vennila, S.K.Saxena, D.Z. Wang, Synthesis, microstructure and optical characterization of Zirconium oxide nanostructures, Ceram. Int. 35(6) (2009) 2401-2408.

[6] A.S. Keiteb, Elias Saion, Azmi Zakaria, Nayereh Soltani, Structural and optical properties of zirconia nanoparticles by thermal treatment synthesis, J. Nanomater. 2016 (2016) 1913609-1-6.
[7] E. Kumar, P. Selvarajan, D. Muthuraj, Synthesis and characterization of $\mathrm{CeO}_{2}$ nanocrystals by solvothermal route, Mater. Res. 16 (2013) 269-276.

[8] H.R. Sahu, G.R. Rao, Characterization of combustion synthesized zirconia powder by UV-vis, IR and other techniques, Bull. Mater. Sci. 23 (2000) 349-354.

[9] T. Zhang, T. Oyama, A. Aoshima, H. Hidaka, J. Zhao, N. Serpone, Photooxidative $\mathrm{N}$-demethylation of methylene blue in aqueous $\mathrm{TiO}_{2}$ dispersions under UV irradiation, Photochem. Photobiol. A 140 (2001) 163-172.

[10] V. Priyanka, V.C. Srivastava, Photocatalytic oxidation of dye bearing wastewater by iron doped zinc oxide, Ind. Eng. Chemp. Res. 52 (2013) 17790 17799. 